\title{
Analisis dan optimasi struktur sasis bus dengan batasan tegangan maksimum dan defleksi pada beban maksimum
}

\author{
Ojo Kurdi ${ }^{1,2}$, Ismoyo Haryanto ${ }^{1,2}$, Agus Suprihanto ${ }^{1}$, Ian Yulianti ${ }^{3}$, Nur \\ Aziyah $^{1}$
}

\author{
${ }^{1}$ Program Studi Teknik Mesin, Universitas Diponegoro \\ Jl. Professor Sudarto, SH, Tembalang, Semarang 50275 \\ ${ }^{2}$ National Center for Sustainable Transportation Technology, Indonesia \\ Center for Research and Community Services (CRCS) Building, Lv. 2, Institut Teknologi Bandung \\ Jl. Ganesa No.10, Kota Bandung, Jawa Barat 40132 \\ ${ }^{3}$ Jurusan Fisika, Universitas Negeri Semarang \\ Email korespondensi: ojokurdi@ft.undip.ac.id
}

\begin{abstract}
Abstrak
Sasis merupakan bagian penting dari sebuah kendaraan, yang membentuk kerangka dari sebuah kendaraan. Sasis harus cukup kaku untuk menahan kejutan, twist, getaran dan tekanan lainnya. Pertimbangan penting dalam desain sasis adalah memiliki kekakuan lentur yang memadai disertai kekuatan untuk karakteristik handling yang lebih baik. Oleh karena itu tegangan maksimum, dan defleksi merupakan kriteria penting untuk desain sasis. Penelitian ini bertujuan untuk menentukan desain paling optimal dari ketiga desain sasis tipe C, I dan Rectangular Box (Hollow) dengan metode optimasi ASO dan MOGA. Simulasi pembebanan static structural dan optimasi dilakukan dengan menggunakan Finite Element Analysis. Hasilnya menunjukan bahwa tegangan maksimum terjadi pada cross section C besar tegangan 73,235 Mpa, dan defleksi sebesar 1,5455 mm. Hasil analisis pembebanan statik menunjukan bahwa desain tipe Rectangular Box (Hollow) jauh lebih optimal daripada tipe C ataupun I. Berdasarkan optimasi pada sasis bus tipe Rectangular Box (Hollow) dengan dua metode tersebut, hasil terbaik menggunakan metode ASO dengan nilai massa optimum sebesar 682,57 kg (persentase penurunan massa sebesar 1,224\%) dengan equivalent (von-misses) stress sebesar 53,557 MPa dan total deformasi sebesar 1,1847 mm. Sementara itu, dengan metode MOGA diperoleh massa optimum sebesar 686,83 kg dengan equivalent (vonmisses) stress 53,517 MPa dan total deformasi sebesar 1,1809 mm. Terjadi penurunan massa sebesar 0,608\%.
\end{abstract}

Kata kunci: adaptive single objective (ASO), defleksi, multi objective genetic algorithm (MOGA), tegangan maksimum

\begin{abstract}
Chassis is an important part of a vehicle, which forms the frame of a vehicle. Chassis must be rigid enough to withstand shock, twist, vibration and other stresses. An important consideration in chassis design is having adequate bending stiffness along with strength for better handling characteristics. Therefore, the maximum stress, and deflection are important criterias for chassis design. The purpose of this study is to determine the most optimum design of the three chassis designs of type C, I and Rectangular Box (Hollow) using ASO and MOGA optimization methods. Simulatation of structural static loading and optimization were done using Finite Element Analysis. The results showed that the maximum stress occurs in the cross-section C with a stress of $73.235 \mathrm{Mpa}$, and a deflection of $1.5455 \mathrm{~mm}$. The results of the static load analysis showed that the design of the type Rectangular Box (Hollow) is more optimal than type C or I. Based on the optimization on the Rectangular Box (Hollow) type bus chassis with the two methods, the best results use the ASO method with an optimum mass value of 682, $57 \mathrm{~kg}$ (mass reduction percentage of 1.224\%) with equivalent (von-misses) stress of $53.557 \mathrm{MPa}$ and total deformation of $1.1847 \mathrm{~mm}$. Meanwhile, from MOGA method it was found that the optimum mass value was $686.83 \mathrm{~kg}$ with equivalent (von-misses) stress of $53.517 \mathrm{MPa}$ and the total deformation was $1.1809 \mathrm{~mm}$. There was a decrease in mass of $0.608 \%$.
\end{abstract}

Keywords: adaptive single objective (ASO), deflection, multi objective genetic algorithm (MOGA), maximum stress 


\section{Pendahuluan}

Chassis merupakan bagian penting dari sebuah kendaraan, yang membentuk kerangka dari sebuah kendaraan. Chassis berfungsi sebagai kerangka yang bekerja untuk menopang tubuh dan bagian kendaraan yang lainnya seperti berat kendaraan, mesin serta penumpang. Chassis harus cukup kaku untuk menahan kejutan, twist, getaran dan tekanan lainnya. Fungsi utamanya adalah membawa beban maksimum yang dirancang dengan aman untuk semua kondisi saat beroperasi. Untuk kontruksi rangka chassis itu sendiri harus memiliki kekuatan, ringan dan mempunyai nilai kelenturan. Pertimbangan penting dalam desain chassis adalah memiliki kekakuan lentur yang memadai disertai kekuatan untuk karakteristik handling yang lebih baik. Oleh karena itu tegangan maksimum, dan defleksi merupakan kriteria penting untuk desain chassis [1]-[4]

Berat chassis merupakan objek penting yang harus dikurangi agar berat keseluruhan kendaraan menjadi lebih ringan [1], [5]-[8]. Pengurangan berat kendaraan secara umum akan mengurangi konsumsi bahan bakar dan meningkatkan performanya [6], [9][13] . Oleh karena itu banyak peneliti yang melakukan optimasi struktur chassis untuk mendapatkan berat chassis dan kendaraan yang seringan mungkin tanpa mengurangi unjuk kerja kendaraan tersebut [5], [14]-[19]

Pada penelitian sebelumnya [2] menjelaskan bahwa pada penelitian chassis kendaraan dari bus TAT LP 912 Diesel BS4. Dimodelkan empat chassis dengan penampang melintang yang berbeda yaitu tipe C, I, Rectangular Box (Hollow) dan Rectangular Box (Intermediate). Perhitungan yang dilakukan pada HyperMesh menyimpulkan bahwa bagian Rectangular Box (intermediate) lebih aman dibawah beban 12,825 ton yang merupakan total berat kendaraan termasuk berat kendaraan kotor dan berat penumpang. Dari hasil tersebut, bahwa bagian Rectangular Box (Intermediate) lebih kuat dari pada chassis dengan spesifikasi desain tipe C, I dan Rectangular Box (Hollow). Bagian Rectangular Box (Intermediate) memiliki defleksi paling rendah yaitu 1,839 $\mathrm{mm}$ pada keempat tipe chassis dari penampang melintang yang berbeda.

Mengurangi berat kendaraan dengan batasan (constraint) tegangan maksimum dan defleksi maksimum diperlukan dalam suatu proses optimasi agar didapat massa yang optimum. Dengan menggunakan optimasi struktur (structural optimization), variabel yang akan dioptimasi adalah ketebalan dari longitudinal member dan cross member sebagai penyusun chassis bus tersebut, sehingga massa dapat berkurang dan meningkatkan efisiensi energi, meningkatkan dinamika kendaraan serta dapat meningkatkan kinerja kendaraan secara keseluruhan [20], [21]. Pada penelitian sebelumnya menjelaskan bahwa Optimasi struktur rangka bus yang dilakukan dengan software Hyperworks menghasilkan penurunan massa sebesar $5,4 \%$ (reduksi $75 \mathrm{~kg}$ ) dari massa total sebesar $1390 \mathrm{~kg}$ [20]. Ada dua metode optimasi yang akan digunakan dalam penelitian ini, yang pertama adalah Adaptive Single Objective (ASO) dimana metode ini adalah metode optimasi matematis berbasis algoritma gradient-based untuk mencapai hasil optimumnya. Metode yang kedua adalah metode Multi-Objective Genetic Algorithm (MOGA) dimana metode ini adalah metode optimasi non-gradien, dimana memanfaatkan informasi dalam vektor populasi dari suatu generasi untuk menyesuaikan arah pencarian. Ada tiga operator di dalam DE yaitu: Mutasi, crossover dan seleksi.

Dalam penelitian ini, penulis menganalisis struktur chassis bus dengan memvariasikan penampang melintangnya yaitu dengan tipe cross section $\mathrm{C}$, I dan Rectangular Box (Hollow). Untuk itu digunakan suatu software CAD, untuk memodelkan chassis, serta software Finite Element Analysis (FEA) untuk menganalisa besar tegangan maksimum, dan defleksi maksimum dari chassis bus tersebut, hingga dilakukan optimasi ketebalan longitudinal member dan cross member pada struktur chassis bus dengan penampang melintang tipe Rectangular Box (Hollow).

\section{Metode}

Dalam kajian ini, optimasi struktur chassis bus untuk meminimalkan berat kendaraan dengan batasan tegangan maksimum dan defleksi maksimum, hal yang harus dilakukan sebelum dianalisis dan dioptimasi adalah melakukan pemodelan struktur chassis bus dengan bantuan software CAD. Dalam melakukan pemodelan chassis bus dengan menggunakan software.

Dalam kajian ini dibuat 3 tipe model chassis dengan cross section yang berbeda yaitu tipe $C, I$ dan Rectangular Box (Hollow). Sehingga dikelompokkan jenis-jenis longitudinal member dan cross member, yang digunakan sesuai dengan tipe cross section masing-masing.

Struktur chassis bus yang digunakan sebagai analisis dan optimasi pada kajian ini termasuk ke dalam kategori bus besar dengan kapasitas maksimum 41 kursi, spesifikasi lengkap dapat dilihat pada Tabel 1. 
Tabel 1. Spesifikasi chassis bus

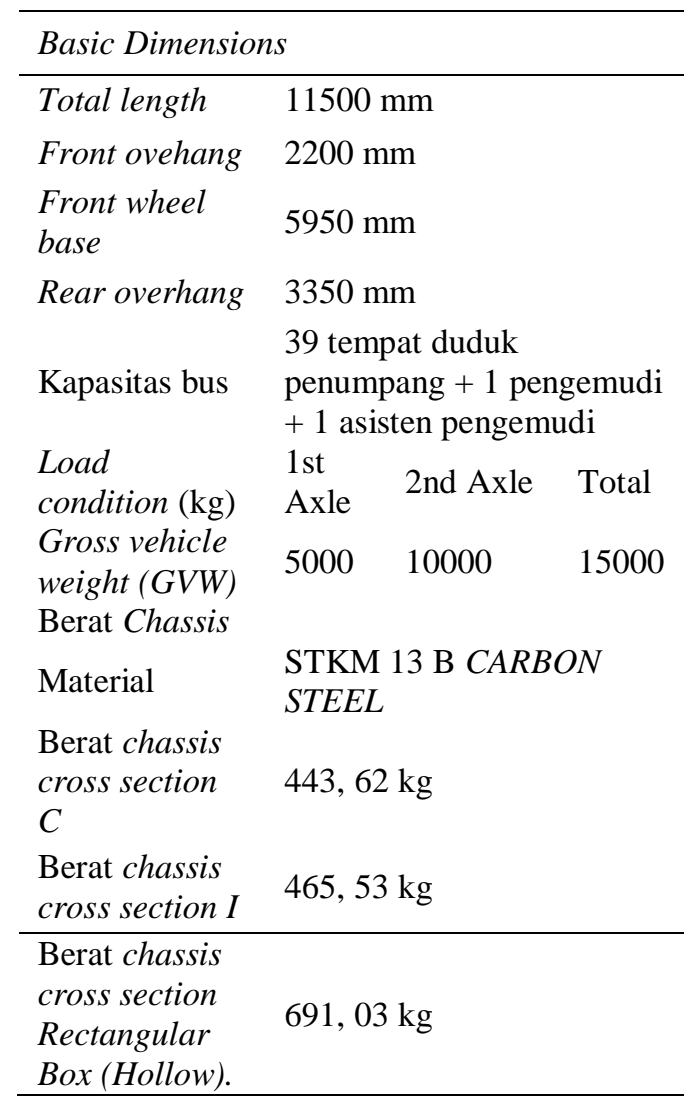

\section{Simulasi Analisis Struktur Statis}

Simulasi analisis pembebanan struktur statis pada chassis bus dilakukan untuk mengetahui besar tegangan maksimum, defleksi dan faktor keamanan yang dimiliki oleh suatu model chassis bus pada kondisi-kondisi tertentu. Pada kajian ini menggunakan software finite element analysis (FEA) untuk melakukan simulasi analisis pembebanan statis (static structural analysis). Model yang telah dibuat dengan software disimpan dalam bentuk ekstensi (.sldasm) yang merupakan file assembly terakhir dari pemodelan chassis bus tersebut.

\section{Kondisi Batas dan Pembebabanan}

Kondisi batas yang digunakan berupa fixed constraint atau tumpuan jepit, dimana pada tumpuan jenis ini, perpindahan translasi dan rotasi tidak diijinkan untuk seluruh arah sumbu. Kondisi batas ini menggambarkan keadaan yang sebenarnya. Letak kondisi batas ini pada model, yaitu pada sambungan antara chassis dengan struktur bagian atas roda depan dan belakang. Sedangkan beban yang ditumpu oleh chassis adalah beban statis yang berasal dari penumpang, tempat duduk, body dan sistem pendingin. Distribusi beban pada model ditunjukkan pada Gambar 1.

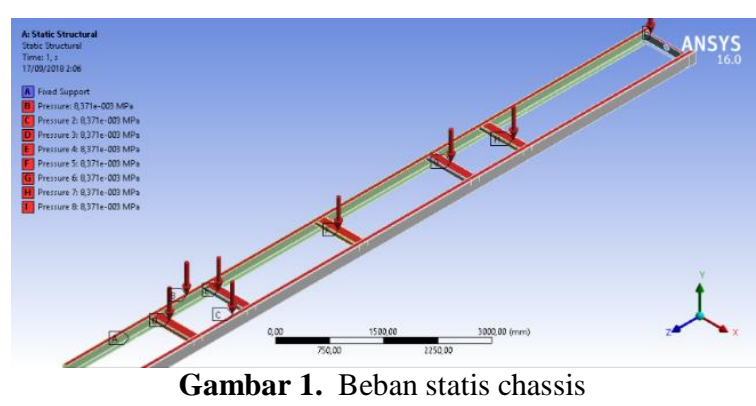

\section{Hasil dan Pembahasan}

Hasil simulasi berupa static structural yaitu equivalent (von-misses) stress, total deformation dan safety factor. Hasil simulasi untuk chassis dengan cross section C ditunjukkan pada Gambar 2. Dari data hasil simulasi pembebanan statis kemudian dikelompokan pada Tabel 2.

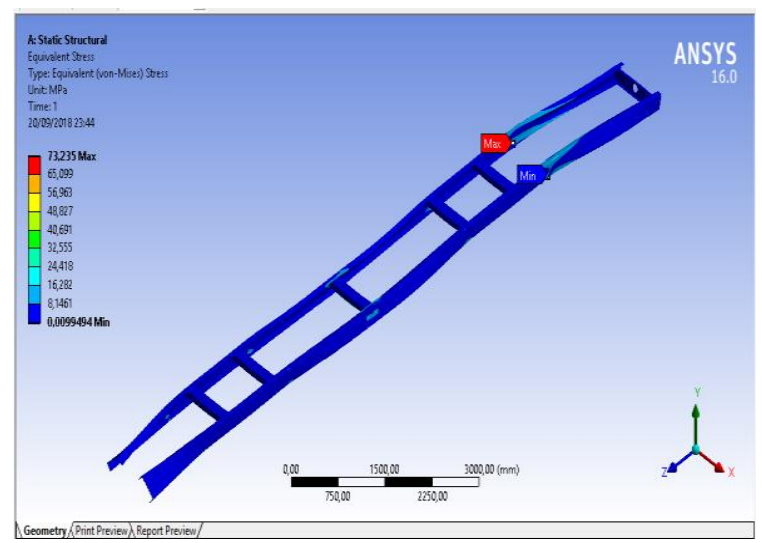

(a)

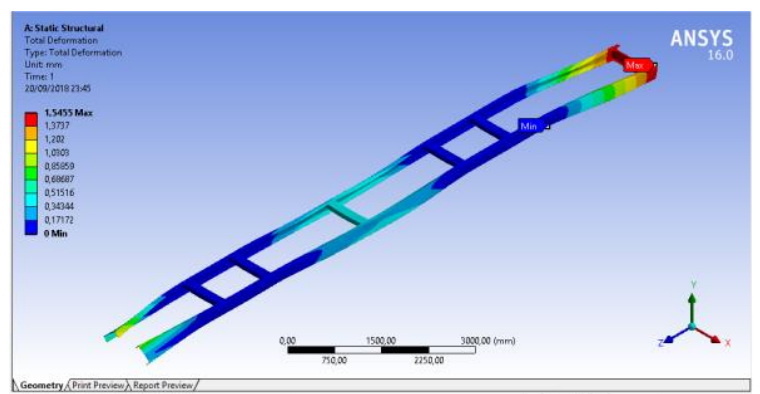

(b)

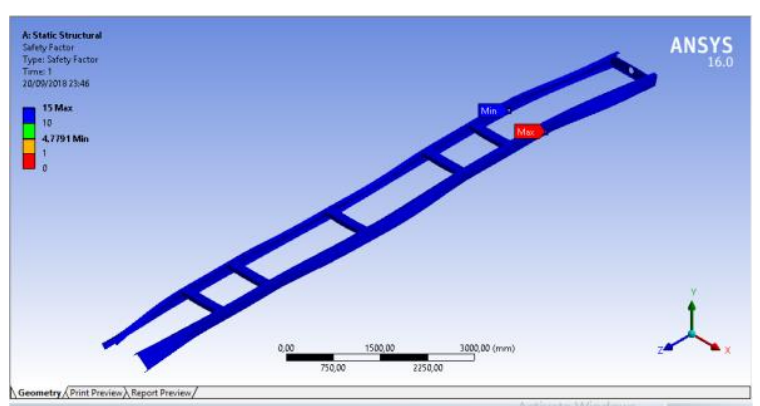

(c)

Gambar 2. Hasil simulasi chassis dengan cross section C; a) tegangan von Misses; b). total deformation; c) safety factor 
Tabel 2. Hasil simulasi pembebanan statis

\begin{tabular}{|c|c|c|c|c|}
\hline No & Profil & $\begin{array}{c}\text { Equivalent } \\
\text { (von- } \\
\text { Misses) } \\
\text { stress } \\
(M P a)\end{array}$ & $\begin{array}{c}\text { Total } \\
\text { deformation } \\
\quad(\mathrm{mm})\end{array}$ & $\begin{array}{l}\text { Safety } \\
\text { factor }\end{array}$ \\
\hline 1 & $\mathrm{C}$ & 73,235 & 1,5455 & 4,7791 \\
\hline 2 & I & 58,21 & 1,5323 & 6,0127 \\
\hline 3 & Hollow & 53,655 & 1,1848 & 6,5232 \\
\hline
\end{tabular}

\section{Optimasi Struktur Chassis Bus}

Pada proses optimasi struktur chassis bus ini, dilakukan dengan batasan tegangan maksimum dan defleksi maksimum, sehingga mampu meminimalkan massa chassis bus tanpa mengurangi keamanan dari chassis bus tersebut dan jenis optimasi yang dilakukan adalah jenis optimasi ukuran (size optimization). Dalam kondisi ini, ketebalan dari setiap longitudinal member dan cross member yang menyusun struktur chassis bus tersebut dioptimasi dengan dua metode optimasi yaitu metode optimasi Adaptive Single Objective (ASO) dan metode optimasi Multi Objective Genetic Algorithm (MOGA).

Hasil optimasi ketebalan dengan metode Adaptive Single Objective (ASO) dapat dilihat pada Gambar 3 untuk konvergensi massa, equivalent (von-misses) stress dan total deformation. Dan hasil optimasi ketebalan dengan metode Multi Objective Genetic Algorithm (MOGA) dapat dilihat pada Gambar 4.

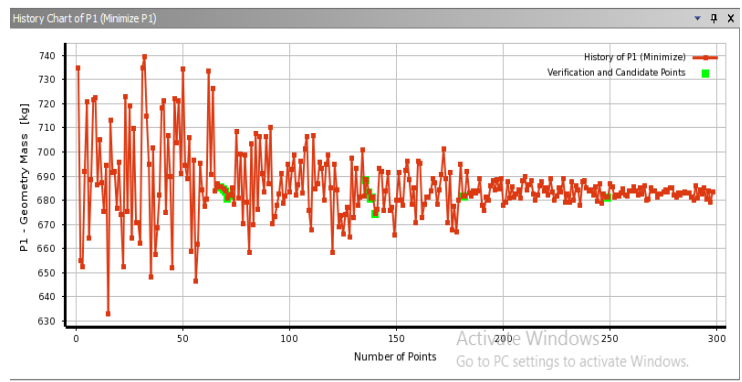

(a)

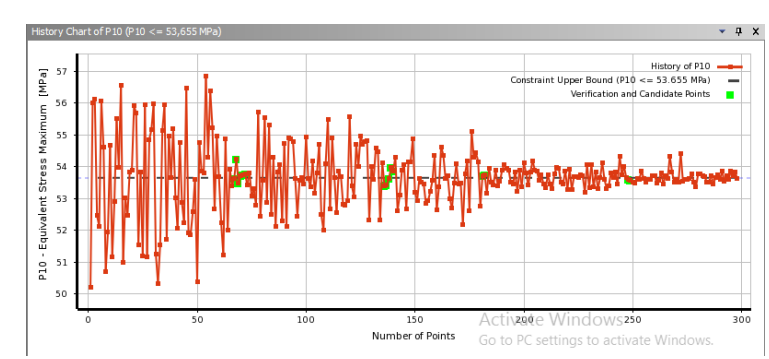

(b)

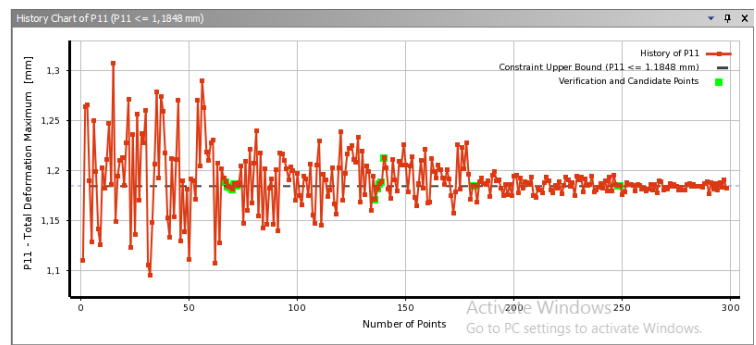

(c)

Gambar 3. Hasil konvergensi metode ASO; a) massa; b). von Misses; c). total deformation

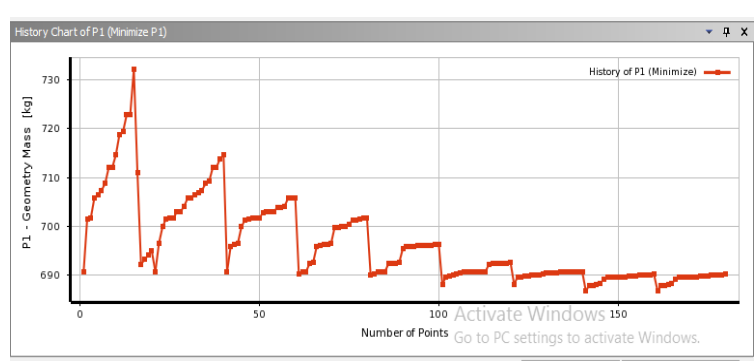

(a)

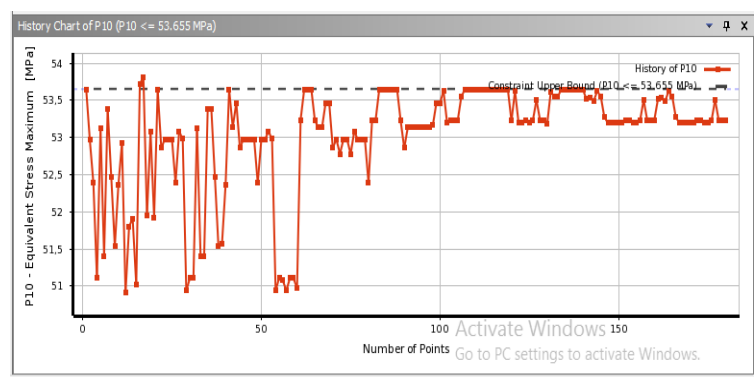

(b)

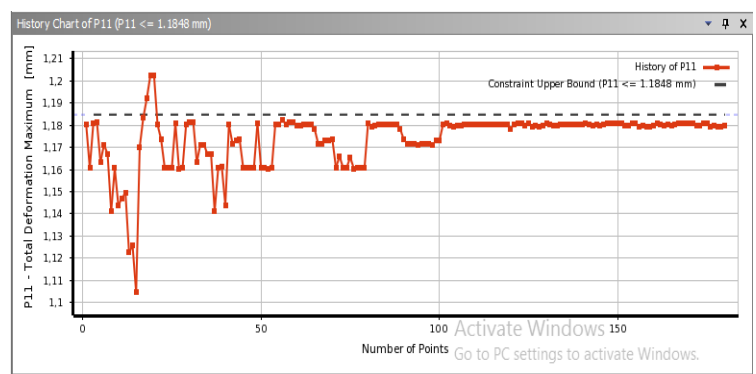

(c)

Gambar 3. Hasil konvergensi metode MOGA; a) massa; b). von Misses; c). total deformation

Setelah optimasi selesai, hasil optimasi dinyatakan dalam bentuk kandidat, kandidat terbaik diambil, karena masih dalam bentuk desimal yang sangat banyak, diperlukan penyederhanaan terhadap hasil optimasi. Hasil analisis struktur sebelum dan sesudah optimasi dapat dilihat dari Tabel 3. 
Tabel 3. Perubahan massa, equivalent (von-misses) stress dan total deformation sebelum dan sesudah optimasi

\begin{tabular}{lcccc}
\hline & $\begin{array}{c}\text { Massa } \\
(\mathrm{kg})\end{array}$ & $\begin{array}{c}\text { Equivalen } \\
t(\text { Von- } \\
\text { misses }) \\
\text { stress }\end{array}$ & $\begin{array}{c}\text { Total } \\
\text { defor } \\
\text { mation }\end{array}$ & $\begin{array}{c}\text { Deviasi } \\
\text { massa } \\
(\%)\end{array}$ \\
\hline Awal & 691,03 & 53,655 & 1,1848 & 0 \\
$\begin{array}{l}\text { Optimasi } \\
\text { ASO }\end{array}$ & 682,57 & 53,557 & 1,1847 & 1,224 \\
$\begin{array}{l}\text { Optimasi } \\
\text { MOGA }\end{array}$ & 686,83 & 53,517 & 1,1809 & 0,608 \\
\hline
\end{tabular}

Dapat dilihat bahwa dari semua metode yang diterapkan pada optimasi ketebalan struktur chassis bus, metode terbaik adalah metode optimasi Adaptive Single Objective (ASO). Dari tabel dapat dilihat penurunan massa kendaraan dari $691,03 \mathrm{~kg}$ menjadi $682,57 \mathrm{~kg}$ atau reduksi massa sebesar $8,46 \mathrm{~kg}$.

\section{Kesimpulan}

Hasil analisis pembebanan statis menunjukkan bahwa desain dengan cross-sectional Rectangular Box (Hollow) menunjukan jauh lebih optimal daripada chassis dengan spesifikasi tipe $\mathrm{C}$ ataupun I karena tegangan paling minimum terjadi pada cross section Rectangular Box (Hollow) nilai tegangan sebesar 53,655 MPa, dan total deformation sebesar 1,1848 mm. Berdasarkan optimasi pada chassis bus tipe Rectangular Box (Hollow) dengan dua metode tersebut, dapat disimpulkan hasil terbaik adalah menggunakan metode Adaptive-Single Objective (ASO) dengan nilai massa optimum sebesar $682,57 \mathrm{~kg}$ (persentase penurunan massa sebesar 1,224\%) dengan equivalent (von-misses) stress sebesar $53,557 \mathrm{MPa}$ dan total deformation sebesar 1,1847 mm. Sedangkan hasil optimasi metode Multi-Objective Genetic Algorithm (MOGA), massa hasil optimasi didapat sebesar 686,83 kg dengan equivalent (von-misses) stress $53,517 \mathrm{MPa}$ dan total deformation sebesar $1,1809 \mathrm{~mm}$. Terjadi penurunan massa sebesar $0,608 \%$.

\section{Penghargaan}

Kajian ini sebagian didanai oleh USAID dibawah program SHERA dengan nomor projek AID-497-A16-00004

\section{Daftar Pustaka}

[1] I. Tikekar and A. Damle, "Weight Reduction of Heavy Duty Truck Chassis Through Material Optimization," Int. J. Eng. Res. Gen. Sci., vol. 4, no. 3, pp. 140-146, 2016.

[2] A. Singh, V. Soni, and A. Singh, "Structural Analysis of Ladder Chassis for Higher Strength," Int. J. Emerg. Technol. Adv. Eng., vol. 4, no. 2, 2014.

[3] H. F. Teo, "Statics and dynamics structural analysis of a 4.5 ton truck chassis," J. Mek., no. 24, pp. 56-67, 2007.

[4] C. Karaoğlu and N. Sefa Kuralay, "Stress analysis of a truck chassis with riveted joints," Finite Elem. Anal. Des., vol. 38, no. 12, pp. 1115-1130, Oct. 2002.

[5] H. Patel, K. C. Panchal, and C. S. Jadav, "Structural Analysis of Truck Chassis Frame and Design Optimization for Weight Reduction," Int. J. Eng. Adv. Technol., vol. 2, no. 4, pp. 665-668, 2013.

[6] P. Doke, M. Fard, and R. Jazar, "Vehicle concept modeling: A new technology for structures weight reduction," Procedia Eng., vol. 49, pp. 287-293, 2012.

[7] J. Decicco and M. Ross, "Recent advances in automotive technology and the costeffectiveness of fuel economy improvement," Transp. Res. Part D Transp. Environ., vol. 1, no. 2, pp. 79-96, Dec. 1996.

[8] K.-P. Glaeser and M. A. Ritzinger, "Comparison of the Performance of Heavy Vehicles Results of the OECD Study: 'Moving Freight with Better Trucks,'” Procedia - Soc. Behav. Sci., vol. 48, pp. 106120, 2012.

[9] R. Tolouei and H. Titheridge, "Vehicle mass as a determinant of fuel consumption and secondary safety performance," Transp. Res. Part D Transp. Environ., vol. 14, no. 6, pp. 385-399, Aug. 2009.

[10] D. C. Biggs and R. Akcelik, "Estimating effect of vehicle characteristics on fuel consumption," J. Transp. Eng., vol. 113, no. 1, pp. 101-106, 1987.

[11] S. . Burgess and J. M. . Choi, "A parametric study of the energy demands of car transportation: a case study of two competing commuter routes in the UK," Transp. Res. Part D Transp. Environ., vol. 8, no. 1, pp. 21-36, Jan. 2003.

[12] V. Soloiu, A. Covington, J. Lewis, M. Duggan, J. Lobue, and M. Jansons, "Performance of JP-8 unified fuel in a small bore indirect injection diesel engine for APU applications," SAE Tech. Pap., 2012.

[13] M. Mammetti, D. Gallegos, A. Freixas, and J. Muñoz, "The influence of rolling resistance on fuel consumption in heavy-duty vehicles," SAE Tech. Pap., vol. 2, 2013.

[14] M. Cavazzuti and L. Splendi, "Structural Optimization of Automotive Chassis: Theory, Set Up, Design," Italy Univ. degli Stud. di Modena e Reggio Emila, 2011.

[15] P. Naik, J. Unde, and B. Darekar, "Structural Analysis and Optimization of Hyperloop Pod," pp. 2-7, 2018.

[16] Chandan S N, Vinayaka N, and Sandeep G $\mathrm{M}$, "Design, Analysis and Optimization of Race Car Chassis for its Structural Performance," Int. J. Eng. Res., vol. V5, no. 07, pp. 361-367, 2016.

[17] K. Dalal and C. M. Choudhari, 
"Optimization of 40 Feet Trailer Chassis Based on Structural Static Simulation," Int. J. Mech. Prod. Eng., no. 5, pp. 2320-2092, 2017.

[18] E. Teipen and M. Paas, "Body Structure \& Chassis Optimization," 2011.

[19] P. Chinta and D. L. V. V. Rao, "A New Design and Analysis of BUS Body Structure," IOSR J. Mech. Civ. Eng., vol. 11, no. 5, pp. 39-47, 2014.

[20] M. S. B. A. Razak, M. H. Bin Hasim, and N. A. Bin Ngatiman, "Design of Electric Vehicle Racing Car Chassis using Topology Optimization Method," MATEC Web Conf., vol. 97, no. January, 2017.

[21] H. Singh, "Optimization of Bus Body Structure Using OptiStruct," pp. 1-5. 